\title{
Overexpression of Hypoxia-Inducible Factor-1 $\alpha$ Exacerbates Endothelial Barrier Dysfunction Induced by Hypoxia
}

\author{
Pei Wang ${ }^{a}$ Huabing $\mathrm{Q}^{\mathrm{a}}$ Chunhong Sun Wen He Gang Chen Li Li \\ Fengjun Wang
}

State Key Laboratory of Trauma, Burns and Combined Injury, Institute of Burn Research, Southwest

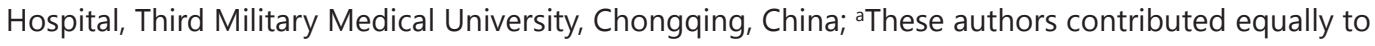
this work

\section{Key Words}

Hypoxia-inducible factor-1 $\alpha \cdot$ Hypoxia $\bullet$ Endothelial cell $\bullet$ Barrier dysfunction $\bullet$ ZO- 1 Occludin - Myosin light chain kinase

\begin{abstract}
Background/Aims: The mechanisms involved in endothelial barrier dysfunction induced by hypoxia are incompletely understood. There is debate about the role of hypoxia-inducible factor- $1 \alpha(\mathrm{HIF}-1 \alpha)$ in endothelial barrier disruption. The aim of this study was to investigate the effect of genetic overexpression of HIF-1 $\alpha$ on barrier function and the underlying mechanisms in hypoxic endothelial cells. Methods: The plasmid pcDNA3.1/V5-His-HIF-1 $\alpha$ was stably transfected into human endothelial cells. The cells were exposed to normoxia or hypoxia. The mRNA and protein expressions of HIF-1 $\alpha$ were detected by RT-PCR and Western blot respectively. The barrier function was assessed by measuring the transendothelial electrical resistance (TER). The Western blot analysis was used to determine the protein expression of glucose transporter-1 (GLUT-1), zonular occludens-1 (ZO-1), occludin, and myosin light chain kinase (MLCK) in endothelial cells. The mRNA expression of proinflammatory cytokines was detected by qRT-PCR. Results: Genetic overexpression of HIF-1 $\alpha$ significantly increased the mRNA and protein expression of HIF-1 $\alpha$ in endothelial cells. The overexpression of HIF$1 \alpha$ enhanced the hypoxia-induced increase of HIF- $1 \alpha$ and GLUT-1 protein expression. HIF$1 \alpha$ overexpression not only exacerbated hypoxia-induced endothelial barrier dysfunction but also augmented hypoxia-induced up-regulation of MLCK protein expression. HIF-1 $\alpha$ overexpression also enhanced IL-1 $\beta$, IL- 6 and TNF- $\alpha$ mRNA expression. Conclusion: We provide evidence that genetic overexpression of HIF-1 $\alpha$ aggravates the hypoxia-induced endothelial barrier dysfunction via enhancing the up-regulation of MLCK protein expression caused by hypoxia, suggesting a potential role for HIF-1 $\alpha$ in the pathogenesis of endothelial barrier dysfunction in hypoxia.
\end{abstract}




\section{Introduction}

The vascular endothelial barrier is a physiological barrier important for maintaining vascular homeostasis and regulating trafficking of macromolecules and blood cells across the vessel wall in the body [1]. Under normal conditions, the vascular endothelial barrier integrity is primarily maintained by tight junction complexes between adjacent endothelial cells, which selectively permit paracellular movement of molecules across the endothelial barrier [1-3]. Disruption of the endothelial barrier function often leads to serious pathophysiological consequences. For example, the increase of endothelial permeability may cause capillary leakage syndrome and tissue edema [4], which may impair the function of vital organs.

There are many stressors that lead to endothelial barrier dysfunction. Among these stressors disrupting the endothelial barrier integrity, hypoxia is the most frequently encountered stress. Hypoxia has been reported to impair the endothelial barrier function, resulting in increased endothelial permeability, and contributing to the development and progression of several diseases involving disrupted vascular homeostasis [5, 6]. Although previous studies have brought some valuable information on the endothelial barrier disruption caused by hypoxic insult [5, 7-9], the precise mechanisms underlying the hypoxiainduced endothelial barrier disruption remain largely unclear.

Hypoxia-inducible factor-1 (HIF-1) is a crucial regulator of the response to hypoxia in mammalian organisms. HIF-1 is a heterodimeric transcription factor consisting of two subunits, HIF- $1 \alpha$ and HIF- $1 \beta$. HIF- $1 \beta$ is constitutively expressed, whereas HIF- $1 \alpha$ is the regulatory subunit that senses tissue oxygen level. The stability, DNA binding capability, and transcriptional activity of the HIF- $1 \alpha$ are directly controlled by the intracellular oxygen concentration [10-14]. Although it is conclusive that the expression of HIF-1 $\alpha$ is induced by hypoxia, ischemia, and inflammation, the role of HIF-1 $\alpha$ in the regulation of endothelial barrier function is still controversial. Therefore, the aim of this study was to investigate the effects of genetic overexpression of HIF-1 $\alpha$ on endothelial barrier function in response to hypoxic insult. The results demonstrated that genetic overexpression of HIF-1 $\alpha$ exacerbated the hypoxia-induced barrier dysfunction by up-regulating myosin light chain kinase (MLCK) in endothelial cell monolayers.

\section{Materials and Methods}

\section{Cell culture and monolayer}

Endothelial cell line VE purchased from KeyGEN Technologies (Nanjing, Jiangsu, China) [15] was maintained at $37^{\circ} \mathrm{C}$ in a culture media composed of RPMI 1640 (Invitrogen, CA), 10\% fetal bovine sera (Invitrogen), $100 \mathrm{U} / \mathrm{ml}$ penicillin, and $100 \mu \mathrm{g} / \mathrm{ml}$ streptomycin. Culture media were changed every 2 days. The cells were subcultured by partial digestion with $0.25 \%$ trypsin and $0.53 \mathrm{mM}$ ethylenediaminetetraacetic acid (EDTA) in $\mathrm{Ca}^{2+}$ - and $\mathrm{Mg}^{2+}$-free PBS. To prepare monolayer, VE cells were seeded at $1.5 \times 10^{5}$ / $\mathrm{cm}^{2}$ and grown as monolayers on $0.1 \%$ collagen-coated permeable polycarbonate membrane Transwell supports (Corning-Costar, MA) with $0.4 \mu \mathrm{m}$ pores, and used for experiments after confluence.

Generation of cells stably overexpressing HIF-1 $\alpha$

Plasmid pcDNA3.1 vector was purchased from Invitrogen. Plasmid pcDNA3.1/V5-His-HIF-1 $\alpha$ containing full length of human HIF-1 $\alpha$ cDNA was described previously [16], and kindly provided by Dr. Richard K. Bruick at University of Texas Southwestern Medical Center. For stable transfection, VE cells grown on culture dish were transfected with pcDNA3.1 or pcDNA3.1/V5-His-HIF-1 $\alpha$ by Lipofectamine 2000

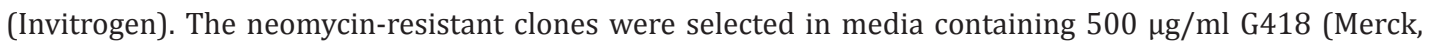
Germany), and transferred into 24-well culture plate with cloning discs (Sigma, MO). The selected clones were expanded in media containing $200 \mu \mathrm{g} / \mathrm{ml} \mathrm{G} 418$, and identified by detecting both mRNA and protein expressions of HIF- $1 \alpha$. 
Treatment of cells with dimethyloxaloyl glycine (DMOG) or hypoxia

To induce HIF-1 $\alpha$ protein accumulation under normoxic condition, cells were treated with or without $1 \mathrm{mmol} / \mathrm{L}$ DMOG (Cayman Chemical, USA) for 12 hours in normoxia. For hypoxia treatment, cells were cultured under hypoxic condition for indicated hours. Briefly, cells were put into a sealed modular incubator chamber (Billups-Rothenberg, $\mathrm{CA}$ ) purged with $1 \% \mathrm{O}_{2}, 5 \% \mathrm{CO}_{2}$, and $94 \% \mathrm{~N}_{2^{\prime}}$ and then the chamber was maintained at $37^{\circ} \mathrm{C}$. Control cells were cultured under normoxic condition.

\section{RNA isolation and RT-PCR analysis}

Cells were washed with ice-cold PBS, and lysed in Trizol (Invitrogen) for total RNA isolation. Cell lysates in TRIzol were sonicated using a sonicator (Tomy Seiko, Tokyo, Japan), and total RNA was extracted with chloroform, precipitated with isopropyl alcohol, and resuspended in diethyl pyrocarbonate (DEPC)treated water. CDNA was generated from total RNA using reverse transcriptase and random hexamer primers included in ThermoScriptRT-PCR System (Invitrogen). The reaction was performed in thermocycler (Bio-Rad, CA) at $25^{\circ} \mathrm{C}$ for $10 \mathrm{~min}, 50^{\circ} \mathrm{C}$ for $45 \mathrm{~min}$, and $85^{\circ} \mathrm{C}$ for $5 \mathrm{~min}$. PCR reaction was performed using ThermoScript RT-PCR System according to the PCR protocol $\left(94^{\circ} \mathrm{C}\right.$ for $5 \mathrm{~min}$, and 35 cycles of $94^{\circ} \mathrm{C}$ for $45 \mathrm{~s}$, $50^{\circ} \mathrm{C}$ for $30 \mathrm{~s}, 72^{\circ} \mathrm{C}$ for $45 \mathrm{~s}$, and $72^{\circ} \mathrm{C}$ for $10 \mathrm{~min}$ ). Primers were $5^{\prime}$-TAA TGT GAG TTC GCA TCT TG-3' and 5 '-CAG GTC ATA GGT GGT TTC TT-3' for detection of HIF- $1 \alpha$, and 5'-TCA ACG GAT TTG GTC GTC GTA TTG-3' and 5'-TGG AAG ATG GTG ATG GGA TT-3' for detection of GAPDH. The PCR products were electrophoresed on $1 \%$ agarose gels and imaging was performed with the ChemiDoc XRS System (Bio-Rad). Images were analyzed using the Quantity One software (Bio-Rad).

\section{Western blot analysis}

Cells were rinsed with ice-cold PBS, lysed with sodium dodecylsulfate-poly-acrylamide gel electrophoresis (SDS-PAGE) sample buffer containing 50mM Tris-HCl, 2\% SDS, 0.1\% bromophenol blue, $5 \% \beta$-mercaptoethanol, $10 \%$ glycerine. After a brief sonication using a sonicator (Tomy Seiko, Tokyo, Japan), cell lysates were centrifuged at $12,000 \mathrm{rpm}$ for $20 \mathrm{~min}$ at $4^{\circ} \mathrm{C}$. The supernatants were harvested to detect protein concentrations by RC DC kit (Bio-Rad). The proteins in supernatants were separated by SDSPAGE and subsequently transferred to a polyvinylidene difluoride (PVDF) membrane (Millipore, MA). The membranes were blocked with 5\% non-fat milk for 1 hour at room temperature, and then incubated with primary antibodies specific for HIF-1 $\alpha$ (1:1000, Millipore), glucose transporter-1 (GLUT-1) (1:1000, Santa Cruz, CA), zonular occludens-1 (ZO-1) (1:1000, Invitrogen), occludin (1:1000, Invitrogen), MLCK (1:1000, Sigma), and $\beta$-actin (1:5000, Sigma) overnight at $4^{\circ} \mathrm{C}$, followed by incubation with horseradish peroxidaseconjugated secondary antibodies (Southern Biotech, Birmingham, AL) for 1 hour at room temperature. After thorough washing, the blots were visualized using Supersignal West Pico Chemiluminescent Kit (Pierce, IL), and imaged using the ChemiDoc XRS System (Bio-Rad). Band densities were quantitated using Quantity One software from Bio-Rad.

\section{Measurement of transendothelial electrical resistance}

Transendothelial electrical resistance (TER) of VE monolayers grown on Transwell supports with 6.5 $\mathrm{mm}$ diameter was determined using a Millicell-ERS voltohmmeter (Millipore) as we described previously [17]. TER was calculated by subtracting the resistance value of the filters and fluids, and normalized to initial value.

\section{Quantitative RT-PCR analysis of proinflammatory cytokines}

Total RNA was extracted from cells using TRIzol reagents (Invitrogen). cDNA was generated from total RNA using First-Strand cDNA Synthesis Kit (OriGene Technologies, Rockville, MD). Quantitative realtime PCR was performed by qSTAR SYBR Master Mix-Low Rox Kit (OriGene Technologies) using the ABI 7500 Fast Real-Time PCR System (Applied Biosystems, Foster City, CA). Analysis was performed according to the manufacturer's protocol. The gene expression of proinflammatory cytokines including IL-1 $\beta$, IL-6 and TNF- $\alpha$ was quantified relative to the expression of GAPDH. The primers used in this study were as follows: IL-1 $\beta$; (Sense) 5'-CCA CAG ACC TTC CAG GAG AAT G-3', (Antisense) 5'-GTG CAG TTC AGT GAT CGT ACA GG-3', IL-6; (Sense) 5'-GCC CAG CTA TGA ACT CCT TCT-3', (Antisense) 5'-GAA GGC AGC AGG CAA CAC3', TNF- $\alpha$; (Sense) 5'-CGA GTG ACA AGC CTG TAG C-3', (Antisense) 5'-GGT GTG GGT GAG GAG CAC AT-3', GAPDH; (Sense) 5'-AAG GTG AAG GTC GGA GTC AA-3', (Antisense) 5'-AAT GAA GGG GTC ATT GAT GG-3'. 


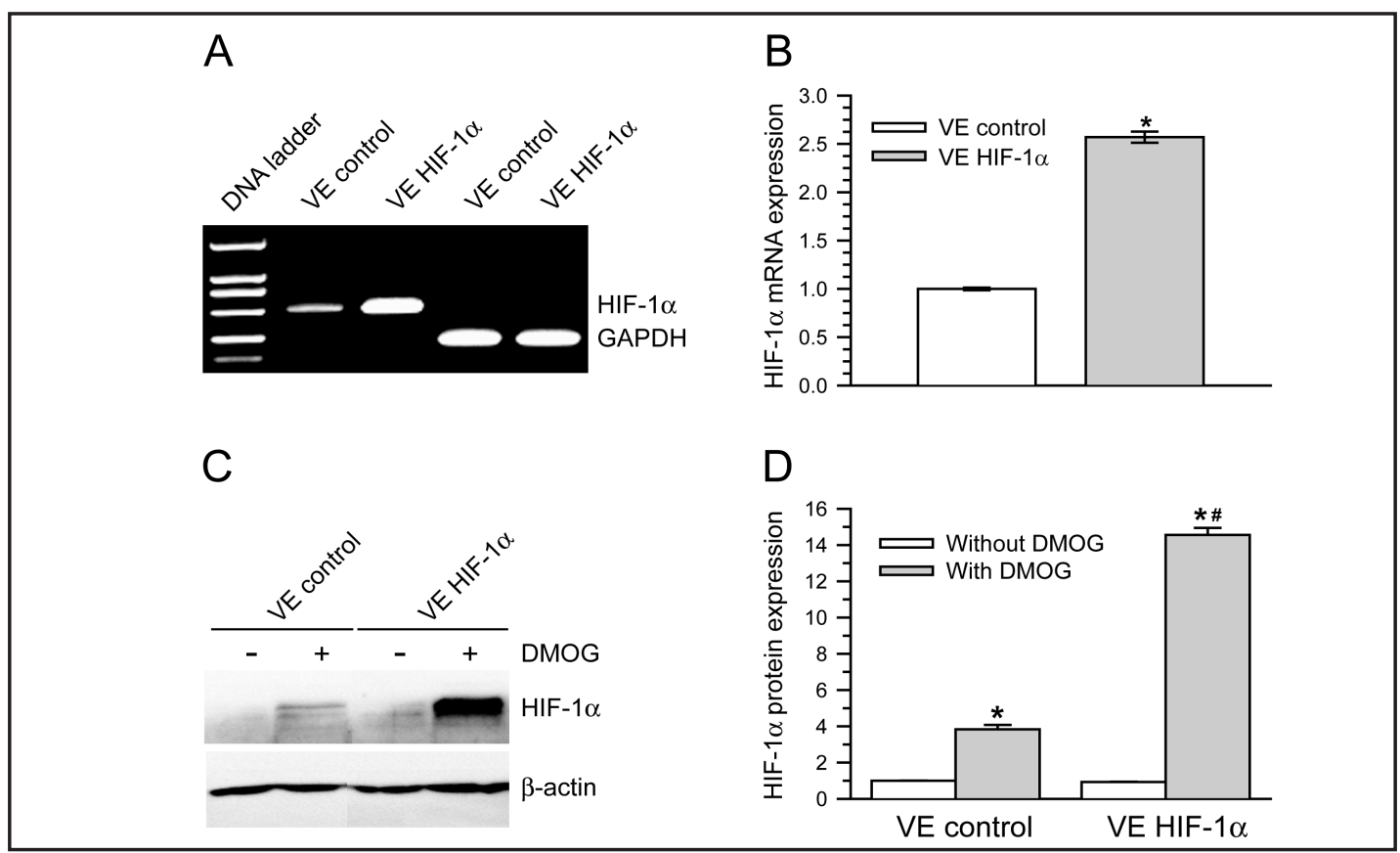

Fig. 1. Identification of cells overexpressing HIF-1 $\alpha$. A \& B. VE cells were stably transfected with plasmid pcDNA3.1/V5-His-HIF-1 $\alpha$. The expression of HIF-1 $\alpha$ mRNA in HIF-1 $\alpha$ transfectants was significantly higher than that in control transfectants. Data are representative of three similar experiments. ${ }^{*}, p<0.05$, compared with VE control. C \& D. Both control and HIF-1 $\alpha$ transfectants were treated without or with $1 \mathrm{mmol} / \mathrm{L} \mathrm{DMOG}$ for 12 hours in normoxia. The expression of HIF-1 $\alpha$ protein in HIF-1 $\alpha$ transfectants treated with DMOG was significantly higher than that in HIF- $1 \alpha$ transfectants without DMOG treatment or control transfectants treated without or with DMOG. Data are representative of three similar experiments. ${ }^{*}, p<0.05$, compared with control or HIF- $1 \alpha$ transfectants without DMOG treatment. \#, $p<0.05$, compared with control transfectants treated with DMOG.

\section{Statistical analysis}

Results are presented as the means \pm SEM. The statistical significance of differences among groups was assessed with One-way ANOVA by SPSS 13.0. Differences between two groups were determined by the Student's $t$ test. $p<0.05$ was considered statistically significant. All reported significance levels represent two-tailed $p$ values.

\section{Results}

Identification of cells overexpressing HIF-1 $\alpha$

To generate endothelial cells overexpressing HIF-1 $\alpha$, the mammalian expression vector pcDNA3.1/V5-His-HIF-1 $\alpha$ containing the full length of human HIF-1 $\alpha$ cDNA was stably transfected into VE cells, and neomycin resistant clones were selected and expanded. We first examined the HIF- $1 \alpha$ mRNA by RT-PCR analysis. No difference in HIF-1 $\alpha$ mRNA expression was seen between non-transfected VE cells and transfection control VE cells transfected with empty vector pcDNA3.1 (data not shown). However, as illustrated in Fig. $1 \mathrm{~A}$ and $\mathrm{B}$, transfection of VE cells with pcDNA3.1/V5-His-HIF- $1 \alpha$ encoding human HIF-1 $\alpha$ clearly demonstrated that HIF-1 $\alpha$ mRNA expression was significantly enhanced in selected cells.

We next assessed HIF- $1 \alpha$ protein expression in these stable transfectants overexpressing human HIF-1 $\alpha$ gene. As shown in Fig. $1 \mathrm{C}$ and D, without DMOG treatment, there was no significant difference in HIF-1 $\alpha$ protein expression between non-transfected VE cells and HIF- $1 \alpha$ transfectants. After treatment with DMOG in normoxia for 12 hours, HIF-1 $\alpha$ protein 


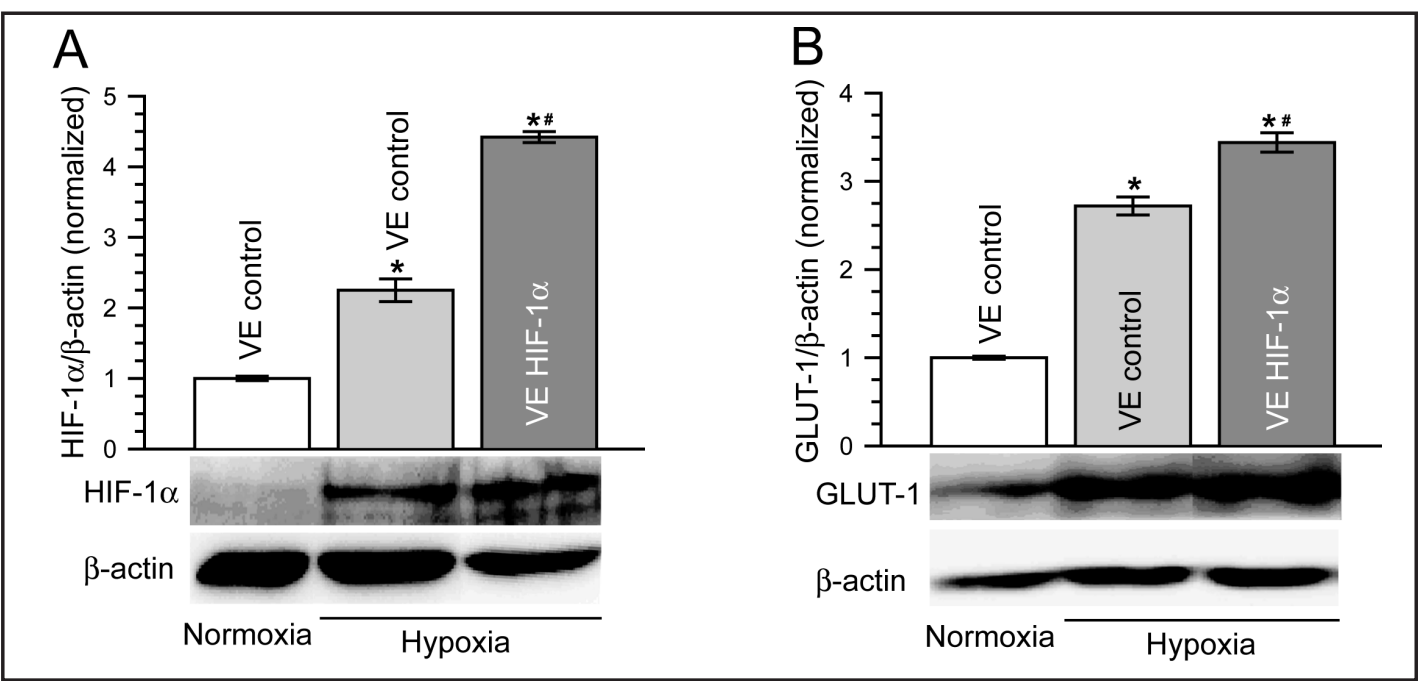

Fig. 2. HIF-1 $\alpha$ overexpression enhances hypoxia-induced HIF-1 activation. A. Exposure of VE cells to hypoxia for 12 hours induced a significant increase of HIF-1 $\alpha$ protein, whereas HIF-1 $\alpha$ overexpression significantly enhanced the hypoxia-induced increase of HIF-1 $\alpha$ protein in VE cells. Data are representative of five similar experiments. *, $p<0.05$, compared with control VE cells exposed to normoxia. \#, $p<0.05$, compared with control VE cells exposed to hypoxia. B. Hypoxic treatment of VE cells for 12 hours induced a significant increase of GLUT-1 protein, which was significantly enhanced by HIF-1 $\alpha$ overexpression. Data are representative of five similar experiments. ${ }^{*}, p<0.05$, compared with control VE cells exposed to normoxia. \#, $p<0.05$, compared with control VE cells exposed to hypoxia.

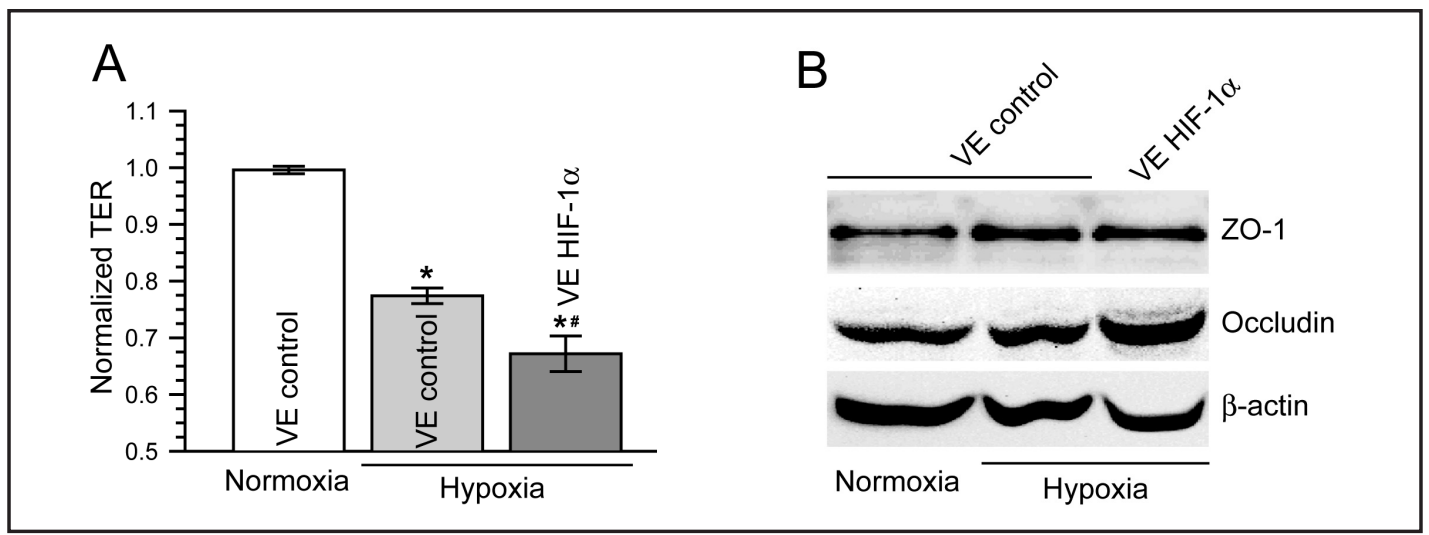

Fig. 3. HIF-1 $\alpha$ overexpression exacerbates hypoxia-induced endothelial barrier dysfunction. A. The barrier function of monolayers was assessed by measuring TER. Treatment of VE monolayers with hypoxia for 24 hours induced a significant decrease of TER, which was significantly enhanced by HIF-1 $\alpha$ overexpression. The data represent the mean $\pm \operatorname{SEM}(\mathrm{n}=9)$. ${ }^{*}, p<0.05$, compared with control VE cells exposed to normoxia. $\#, p<0.05$, compared with control VE cells exposed to hypoxia. B. The monolayers were exposed to normoxia or hypoxia for 24 hours. Neither hypoxia nor HIF-1 $\alpha$ overexpression caused a significant change in the protein expression of both ZO-1 and occludin. Data are representative of five similar experiments.

expression in both non-transfected VE cells and HIF-1 $\alpha$ transfectants increased significantly. In addition, HIF- $1 \alpha$ protein expression in HIF-1 $\alpha$ transfectants treated with DMOG for 12 hours was significantly higher than that in non-transfected VE cells treated with DMOG for 12 hours. Collectively, these data demonstrate that both mRNA and protein expressions of HIF- $1 \alpha$ are enhanced in endothelial cells stably transfected with human HIF-1 $\alpha$ gene. 
Fig. 4. HIF- $1 \alpha$ overexpression augments hypoxiainduced up-regulation of MLCK protein expression. The monolayers were treated with normoxia or hypoxia for 24 hours. Hypoxia treatment up-regulated the expression of MLCK protein, whereas HIF-1 $\alpha$ overexpression enhanced the hypoxia-induced upregulation of MLCK protein. Data are representative of five similar experiments. ${ }^{*}, p<0.05$, compared with control VE cells exposed to normoxia. \#, $p<0.05$, compared with control VE cells exposed to hypoxia.

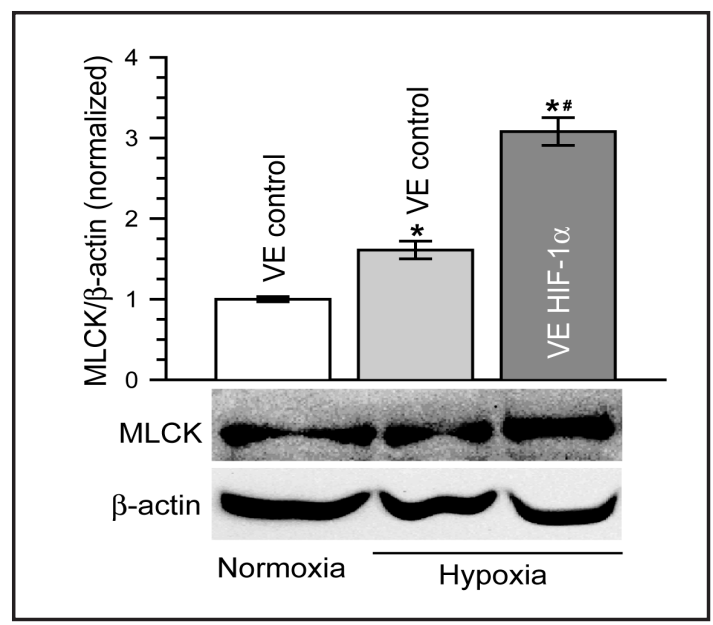

HIF-1 $\alpha$ overexpression enhances hypoxia-induced HIF-1 activation

We have previously demonstrated that HIF- $1 \alpha$ is activated by hypoxia in VE endothelial cells [15]. Thus, in a set of experiments we explored the possibility that HIF$1 \alpha$ overexpression might enhance the hypoxia-induced HIF- $1 \alpha$ activation in VE cells. As illustrated in Fig. 2A, the expression of HIF-1 $\alpha$ protein was significantly increased in control VE cells exposed to hypoxia as compared with control VE cells exposed to normoxia, which is consistent with our previous study [15]. However, the expression of HIF-1 $\alpha$ protein in VE cells transfected with pcDNA3.1/V5-His-HIF-1 $\alpha$ was significantly higher than that in control VE cells exposed to normoxia or hypoxia. Similarly, as shown in Fig. 2B, the protein expression of GLUT-1, an HIF-1 target gene, was also significantly increased in hypoxic VE cells. In addition, the expression of GLUT-1 protein in VE cells transfected with pcDNA3.1/ V5-His-HIF-1 $\alpha$ was significantly higher than that in control VE cells exposed to normoxia or hypoxia. These suggest that the transcriptional activity of HIF-1 in VE cells exposed to hypoxia is enhanced by the transfection with pcDNA3.1/V5-His-HIF-1 $\alpha$. Taken these results together, constitutively stable overexpression of HIF- $1 \alpha$ enhances HIF- $1 \alpha$ activation induced by hypoxia in endothelial cells.

HIF-1 $\alpha$ overexpression exacerbates hypoxia-induced endothelial barrier dysfunction

Previous studies have demonstrated that hypoxia causes barrier dysfunction such as increased paracellular permeability and decreased TER in vascular endothelial cells both in vivo and in vitro. We have previously shown that HIF- $1 \alpha$ is involved in endothelial barrier dysfunction induced by hypoxia [15]. Thus, we investigated the effect of HIF-1 $\alpha$ overexpression on TER, a very sensitive indicator of endothelial barrier function. As shown in Fig. 3A, the TER of hypoxic VE monolayers was significantly lower than that of normoxic VE monolayers, and higher than that of hypoxic VE monolayers stably transfected with HIF-1 $\alpha$ gene. This indicates that constitutively stable overexpression of HIF- $1 \alpha$ exacerbates endothelial barrier dysfunction induced by hypoxia.

It has been reported that alteration of TJ protein expression plays an important role in endothelial barrier disruption induced by hypoxia [18, 19]. Therefore, to determine whether the augmentation of hypoxia-induced endothelial barrier dysfunction by HIF$1 \alpha$ overexpression is accompanied by the changed expression of TJ proteins, we analyzed the expression of TJ proteins ZO-1 and occludin by immunoblot assay. As illustrated in Fig. 3B, as compared with normoxia, hypoxia did not cause a significant change in the protein expression of both ZO-1 and occludin. Similarly, HIF-1 $\alpha$ overexpression also did not remarkably change the protein expression of ZO-1 and occludin. This is in agreement with the previous study revealing that hypoxia alone has little effect on the expression of $\mathrm{TJ}$ proteins including claudin-1, occludin, ZO-1, and ZO-2 while it causes barrier disruption in microvascular endothelial cells [20]. 


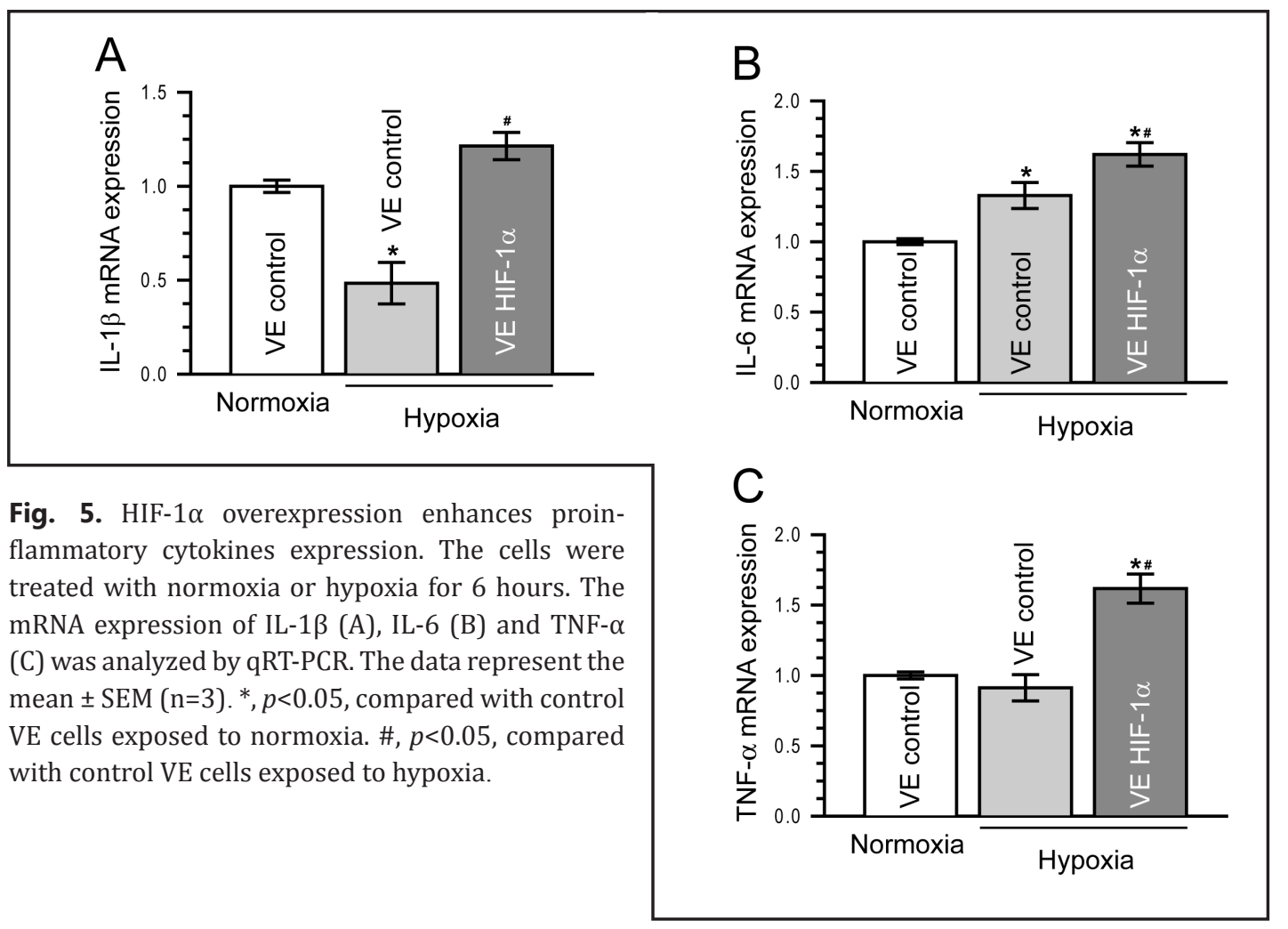

HIF-1 $\alpha$ overexpression augments hypoxia-induced up-regulation of MLCK protein expression

MLCK, a predominant determinant of MLC phosphorylation, has well been reported to be critical to the disruption of barrier function in both vascular endothelia and intestinal epithelia [15, 21-24]. We, along with other investigators, have demonstrated that upregulation of MLCK protein expression plays an essential role in mediating epithelial or endothelial barrier dysfunction caused by a myriad of conditions such as inflammation, hypoxia and burn injury [15, 21-29]. Thus, we considered the possibility that up-regulation of MLCK protein expression is involved in the aggravation of hypoxia-induced endothelial barrier dysfunction caused by HIF-1 $\alpha$ overexpression. As revealed in Fig. 4, the expression of MLCK protein in VE cells was significantly increased by hypoxia treatment. The hypoxiainduced increase of MLCK protein expression was markedly augmented by overexpressing HIF-1 $\alpha$ in VE cells. This is consistent with our previous findings that the hypoxia-induced upregulation of MLCK protein expression in endothelial is inhibited by genetic knockdown of HIF-1 $\alpha$ [15], and that the cytokine-induced increase of MLCK protein in intestinal epithelial cells is suppressed by chemical inhibitors of HIF-1 $\alpha[25,26]$.

A number of proinflammatory cytokines such as IFN- $\gamma$, TNF- $\alpha$ and IL-1 $\beta$ have been shown to induce barrier dysfunction via $\operatorname{MLCK}[17,21-26,28,29]$. Thus, we finally analyzed the mRNA expression of IL-1 $\beta$, IL- 6 and TNF- $\alpha$ to determine if proinflammatory cytokines are associated with the enhancement of MLCK up-regulation. As shown in Fig. 5, hypoxic treatment of VE cells for 6 hours decreased IL-1 $\beta$ mRNA expression, increased IL- 6 mRNA expression, but did not affect TNF- $\alpha$ mRNA expression, as compared with normoxia. However, the mRNA expression of IL-1 $\beta$, IL- 6 and TNF- $\alpha$ in hypoxic VE cells overexpressing HIF- $1 \alpha$ was significantly higher than that in normoxic or hypoxic VE cells. This indicates that HIF-1 $\alpha$ overexpression enhances the expression of proinflammatory cytokines IL-1 $\beta$, IL- 6 and TNF- $\alpha$ in hypoxic condition. 


\section{Discussion}

In this study we evaluated the effects of overexpression of HIF-1 $\alpha$ on barrier function in endothelial cell monolayers exposed to hypoxic insult. The present study reveals two novel findings. First, we show that overexpression of HIF-1 $\alpha$ exacerbates the endothelial barrier dysfunction induced by hypoxia in vitro. Second, we demonstrate that HIF- $1 \alpha$ overexpression augments the hypoxia-induced up-regulation of MLCK protein expression in endothelial cell monolayers. Thus, it is suggested that HIF- $1 \alpha$ may play a critical role in the regulation of endothelial barrier function in response to hypoxic challenge.

HIF is a member of the Per-ARNT-Sim family of basic helix-loop-helix transcription factors that bind specifically to hypoxia response elements at target genes under hypoxia [14]. HIF- $1 \alpha$, the inducible subunit of HIF-1, heterodimerizes HIF-1 $\beta$, the constitutive subunit of HIF-1, forming the functional nuclear transcription factor HIF-1. Over the past two decades HIF-1 has been viewed as a master transcription factor in regulating the hypoxic responses. In addition to hypoxic stress, a variety of factors have been shown to be able to elicit HIF-1 activity even under normoxic conditions. Upon activation, HIF- $1 \alpha$ regulates a wide range of genes involved in many cellular processes such as angiogenesis, glycolytic energy metabolism, oxygen delivery, cell proliferation, and survival, which collectively lead to the adaptive response of cells and tissues [10-14]. Previous reports have shown that the expression of HIF-1 $\alpha$ protein is remarkably increased in endothelial cells exposed to hypoxia $[15,30,31]$. In accordance with the data from these previous studies, our present study demonstrates that hypoxia treatment induced a significantly increased protein expression of HIF- $1 \alpha$ and GLUT-1, an HIF-1 target gene. In addition, genetically constitutive overexpression of HIF- $1 \alpha$ enhanced the protein expression of both HIF- $1 \alpha$ and GLUT- 1 in endothelial cells exposed to hypoxia. This suggests that HIF-1 $\alpha$ overexpression enhances HIF-1 activation induced by hypoxia in endothelial cells.

The activation of HIF-1 is currently believed to play both a beneficial as well as detrimental role in ischemic or hypoxic insult, which may depend on the severity of ischemia/ hypoxia and the specific cell types [32]. Thus, although it is conclusive that ischemia/hypoxia induces the expression of HIF- $1 \alpha$, the role of HIF- $1 \alpha$ in the regulation of barrier function is still controversial. On the one hand, several previous studies have demonstrated that HIF$1 \alpha$ is protective to endothelial or epithelial barrier function under some pathophysiological conditions such as hypoxia or inflammation [33-37]. On the other hand, growing evidence demonstrates that HIF- $1 \alpha$ is deleterious to endothelial or epithelial barrier function during hypoxic, ischemic or inflammatory insult [15, 25, 26, 38-41]. Chemical inhibition of HIF$1 \alpha$ by HIF- $1 \alpha$ inhibitors such as YC-1, 2-methoxyestradiol and oligomycin attenuates the endothelial or epithelial barrier dysfunction induced by hypoxia, ischemia or proinflammatory cytokines. In addition, more interesting is the fact that up-regulation of HIF- $1 \alpha$ expression by cobalt chloride, an HIF- $1 \alpha$ inducer, is able to cause endothelial barrier disruption even in normoxia in vitro, as evidenced by the increased paracellular permeability of endothelial cell monolayers treated with cobalt chloride [38, 42]. Furthermore, an in vivo study has revealed that the endothelial barrier disruption and brain edema induced by hypoxic-ischemic injury are exacerbated by up-regulating HIF-1 $\alpha$ expression with DMOG, an HIF-1 $\alpha$ inducer [43]. Here in this study, we show that hypoxia causes endothelial barrier dysfunction, and that genetic overexpression of HIF-1 $\alpha$ exacerbates the hypoxia-induced endothelial barrier dysfunction in vitro. This coincides with previous report demonstrating that chemical up-regulation of HIF- $1 \alpha$ augments endothelial barrier disruption caused by hypoxia-ischemia [43]. The results from our present study taken together with previous studies by other investigators suggest that HIF-1 $\alpha$ overexpression is deleterious to endothelial barrier function in ischemia or hypoxia, and that HIF- $1 \alpha$ inhibition might be a therapeutic strategy for endothelial barrier dysfunction induced by ischemic or hypoxic injury.

The endothelial barrier function is primarily regulated by intercellular tight junction, which is mainly composed of cytoplasmic proteins, including ZO proteins, and two distinct transmembrane proteins, occludin and claudin [1-3]. Theoretically, the expression alteration 
of the tight junction proteins may lead to endothelial barrier dysfunction. However, conflicting reports have raised debates on the exact role of altered tight junction protein expression in endothelial barrier dysfunction caused by hypoxia. For instance, previous studies have shown that the reduced expression of Z0-1 and claudin- 5 is involved in endothelial barrier disruption caused by hypoxia $[18,19]$. On the contrary, increase of occludin expression has been reported to be associated with the hypoxia-induced endothelial barrier dysfunction [44]. In our present study, we demonstrate that neither hypoxia nor HIF- $1 \alpha$ overexpression causes a significant change in the protein expression of both ZO-1 and occludin while they jeopardize barrier function in endothelial cell monolayers. This is largely coincident with an earlier report that although hypoxia significantly impairs barrier function in microvascular endothelial cells, it does not affect the protein expression of ZO-1, ZO-2, occludin, and claudin-1 [20]. Similarly, it has been demonstrated that hypoxia does not change the mRNA expression of ZO-1, ZO-2, and occludin, whereas it causes barrier dysfunction in brain endothelial cells [45]. Therefore, further studies are needed to assess the effect of hypoxia on the expression of tight junction protein, as well as the exact role of altered tight junction protein expression in endothelial barrier dysfunction induced by hypoxia.

The mechanisms by which HIF-1 $\alpha$ impairs endothelial barrier function are undoubtedly complex. Previous studies have demonstrated that HIF- $1 \alpha$ is involved in barrier dysfunction by inducing the expression of HIF-1 target genes such as vascular endothelial growth factor, inducible nitric oxide synthase [38, 40, 46], aquaporin-4, matrix metalloproteinase-9 [39], macrophage migration inhibitory factor [47], as well as by repressing the expression of vasodilator-stimulated phosphoprotein [48]. However, the activation of MLCK, which in turn leads to an increase of MLC phosphorylation, has been reported to play a critical role in endothelial and intestinal barrier dysfunction induced by hypoxia or inflammation $[21-24,28,29,31,49]$. In addition, our previous studies have revealed that HIF-1 $\alpha-$ dependent up-regulation of MLCK protein is involved in barrier dysfunction induced by hypoxia or proinflammatory cytokines $[15,25,26]$. Therefore, in this study we investigate the effect of HIF-1 $\alpha$ overexpression on the expression of MLCK protein in endothelial cell monolayers exposed to hypoxia. The results show that hypoxia up-regulates the expression of MLCK protein, whereas genetic overexpression of HIF-1 $\alpha$ enhances the hypoxia-induced up-regulation of MLCK protein. It is suggested that the mechanism by which HIF-1 $\alpha$ overexpression exacerbates endothelial barrier dysfunction induced by hypoxia may, at least in part, be attributed to the enhanced up-regulation of MLCK protein expression.

We, along with other investigators, have previously demonstrated that some proinflammatory cytokines such as IFN- $\gamma$, TNF- $\alpha$, IL-1 $1 \beta$, IL- 6 and TNF superfamily member LIGHT induce barrier disruption by activating MLCK-MLC phosphorylation signaling pathway $[17,21-26,28,29,50]$. Thus, in present study we look into the effect of HIF-1 $\alpha$ overexpression on the expression of IL-1 $\beta$, IL- 6 and TNF- $\alpha$ to find out whether proinflammatory cytokines are associated with HIF-1 $\alpha$-mediated barrier dysfunction in endothelial cells. Our results demonstrate that HIF-1 $\alpha$ overexpression enhances the expression of proinflammatory cytokines in hypoxia, which is coincident with the previous studies showing that HIF-1 $\alpha$ induces the up-regulation of proinflammatory cytokines in hypoxia or ischemia $[46,51,52]$. For example, in vivo studies have revealed that partial HIF-1 $\alpha$ deficiency reduces TNF- $\alpha$, IL-1 $\beta$ and IL- 6 mRNA levels in mice subjected to ischemia-reperfusion injury. Therefore, proinflammatory cytokines might be involved in the exacerbation of hypoxia-induced endothelial barrier dysfunction by HIF-1 $\alpha$ overexpression.

In summary, our findings demonstrate that HIF-1 $\alpha$ overexpression in endothelial cell monolayers aggravates the hypoxia-induced barrier dysfunction via enhancing the upregulation of MLCK protein expression induced by hypoxia, suggesting a potential role for HIF-1 $\alpha$ in the pathogenesis of endothelial barrier dysfunction in hypoxia.

\section{Conflict of Interest}

No conflicts of interest exist. 
Wang et al.: HIF-1 $\alpha$ Overexpression Exacerbates Endothelial Barrier Dysfunction in Hypoxia

\section{Acknowledgements}

This work was supported by the National Natural Science Foundation of China (81272087), and the project from State Key Laboratory of Trauma, Burns and Combined Injury (SKLZZ201206).

\section{References}

1 Mehta D, Malik AB: Signaling mechanisms regulating endothelial permeability. Physiol Rev 2006;86:279367.

2 Bazzoni G, Dejana E: Endothelial cell-to-cell junctions: molecular organization and role in vascular homeostasis. Physiol Rev 2004;84:869-901.

-3 Goddard LM, Iruela-Arispe ML: Cellular and molecular regulation of vascular permeability. Thromb Haemost 2013;109:407-415.

4 Fishel RS, Are C, Barbul A: Vessel injury and capillary leak. Crit Care Med 2003;31:S502-S511.

5 Ali MH, Schlidt SA, Hynes KL, Marcus BC, Gewertz BL: Prolonged hypoxia alters endothelial barrier function. Surgery 1998;124:491-497.

6 Sluimer JC, Daemen MJ: Novel concepts in atherogenesis: angiogenesis and hypoxia in atherosclerosis. J Pathol 2009;218:7-29.

7 Schoch HJ, Fischer S, Marti HH: Hypoxia-induced vascular endothelial growth factor expression causes vascular leakage in the brain. Brain 2002;125:2549-2557.

-8 Vogel C, Bauer A, Wiesnet M, Preissner KT, Schaper W, Marti HH, Fischer S: Flt-1, but not Flk-1 mediates hyperpermeability through activation of the PI3-K/Akt pathway. J Cell Physiol 2007;212:236-243.

-9 Kuhlmann CR, Tamaki R, Gamerdinger M, Lessmann V, Behl C, Kempski OS, Luhmann HJ: Inhibition of the myosin light chain kinase prevents hypoxia-induced blood-brain barrier disruption. J Neurochem 2007;102:501-507.

10 Semenza GL: Regulation of mammalian 02 homeostasis by hypoxia-inducible factor 1 . Ann Rev Cell Dev Biol 1999;15:551-578.

11 Semenza GL: HIF-1 and human disease: one highly involved factor. Genes Dev 2000;14:1983-1991.

12 Semenza GL: HIF-1 and mechanisms of hypoxia sensing. Curr Opin Cell Biol 2001;13:167-171.

13 Semenza GL: Life with oxygen. Science 2007;318:62-64.

14 Semenza GL: Regulation of oxygen homeostasis by hypoxia-inducible factor 1. Physiology 2009;24:97-106.

15 Qi H, Wang P, Liu C, Li M, Huang Y, Wang S, Wang F: Involvement of HIF-1 $\alpha$ in MLCK-dependent endothelial barrier dysfunction in hypoxia. Cell Physiol Biochem 2011;27:251-262.

16 Burick RK: Expression of the gene encoding the proapoptotic Nip3 protein is induced by hypoxia. Proc Natl Acad Sci USA 2000;97:9082-9087.

17 Cao M, Wang P, Sun C, He W, Wang F: Amelioration of IFN- $\gamma$ and TNF- $\alpha$-induced intestinal epithelial barrier dysfunction by berberine via suppression of MLCK-MLC phosphorylation signaling pathway. PLoS One 2013;8:e61944.

18 Koto T, Takubo K, Ishida S, Shinoda H, Inoue M, Tsubota K, Okada Y, Ikeda E: Hypoxia disrupts the barrier function of neural blood vessels through changes in the expression of claudin-5 in endothelial cells. Am J Pathol 2007;170:1389-1397.

19 Zhu H, Wang Z, Xing Y, Gao Y, Ma T, Lou L, Lou J, Gao Y, Wang S, Wang Y: Baicalin reduces the permeability of the blood-brain barrier during hypoxia in vitro by increasing the expression of tight junction proteins in brain microvascular endothelial cells. J Ethnopharmacol 2012;141:714-720.

20 Mark KS, Davis TP: Cerebral microvascular changes in permeability and tight junctions induced by hypoxia-reoxygenation. Am J Physiol Heart Circ Physiol 2002;282:H1485-H1494.

21 Wang F, Graham WV, Wang Y, Witkowski ED, Schwarz BT, Turner JR: Interferon- $\gamma$ and tumor necrosis factor- $\alpha$ synergize to induce intestinal epithelial barrier dysfunction by up-regulating myosin light chain kinase expression. Am J Pathol 2005;166:409-419.

22 Ma TY, Boivin MA, Ye D, Pedram A,Said HM: Mechanism of TNF- $\alpha$ modulation of Caco-2 intestinal epithelial tight junction barrier: role of myosin light-chain kinase protein expression. Am J Physiol Gastrointest Liver Physiol 2005;288:G422-G430. 
Wang et al.: HIF-1 $\alpha$ Overexpression Exacerbates Endothelial Barrier Dysfunction in Hypoxia

23 Wang F, Schwarz BT, Graham WV, Wang Y, Su L, Clayburgh DR, Abraham C, Turner JR: IFN- $\gamma$-Induced TNFR2 up-regulation is required for TNF-dependent intestinal epithelial barrier dysfunction. Gastroenterology 2006;131:1153-1163.

24 Schwarz BT, Wang F, Shen L, Clayburgh DR, Su L, Wang Y, Fu YX, Turner JR: LIGHT signals directly to intestinal epithelia to cause barrier dysfunction via cytoskeletal and endocytic mechanisms. Gastroenterology 2007;132:2383-2394.

-25 Liu H, Li M, Wang P, Wang F: Blockade of hypoxia-inducible factor- $1 \alpha$ by YC- 1 attenuates interferon- $\gamma$ and tumor necrosis factor- $\alpha$-induced intestinal epithelial barrier dysfunction. Cytokine 2011;56:581-588.

26 Liu H, Wang P, Cao M, Li M, Wang F: Protective role of oligomycin against intestinal epithelial barrier dysfunction caused by IFN- $\gamma$ and TNF- $\alpha$. Cell Physiol Biochem 2012;29:799-808.

27 Chen C, Wang P, Su Q, Wang S, Wang F: Myosin light chain kinase mediates intestinal barrier disruption following burn injury. PLoS One 2012;7:e34946.

28 Al-Sadi R, Ye D, Dokladny K, Ma TY: Mechanism of IL-1 $\beta$-induced increase in intestinal epithelial tight junction permeability. J Immunol 2008;180:5653-5661.

29 Al-Sadi R, Guo S, Dokladny K, Smith MA, Ye D, Kaza A, Watterson M, Ma TY: Mechanism of interleukin-1 $\beta$ induced-increase in mouse intestinal permeability in vivo. J Interf Cytok Res 2012;32:474-484.

30 Witt KA, Mark KS, Huber J, Davis TP: Hypoxia-inducible factor and nuclear factor kappa-B activation in blood-brain barrier endothelium under hypoxic/reoxygenation stress. J Neurochem 2007;102:501-507.

-31 Aslam M, Schluter KD, Rohrbach S, Rafiq A, Nazli S, Piper HM, Noll T, Schulz R, Gunduz D: Hypoxiareoxygenation-induced endothelial barrier failure: role of RhoA, Rac1 and myosin light chain kinase. J Physiol 2013;591:461-473.

-32 Singh N, Sharma G, Mishra V, Raghubir R: Hypoxia inducible factor-1: its potential role in cerebral ischemia. Cell Mol Neurobiol 2012;32:491-507.

33 Morote-Garcia JC, Rosenberger P, Kuhlicke J, Eltzschig HK: HIF-1-dependent repression of adenosine kinase attenuates hypoxia-induced vascular leak. Blood 2008;111:5571-5580.

-34 Furuta GT, Turner JR, Taylor CT, Hershberg RM, Comerford K, Narravula S, Podolsky DK, Colgan SP: Hypoxia-inducible factor 1-dependent induction of intestinal trefoil factor protects barrier function during hypoxia. J Exp Med 2001;193:1027-1034.

-35 Karhausen J, Furuta GT, Tomaszewski JE, Johnson RS, Colgan SP, Haase VH: Epithelial hypoxia-inducible factor-1 is protective in murine experimental colitis. J Clin Invest 2004;114:1098-1106.

-36 Robinson A, Keely S, Karhausen J, Gerich ME, Furuta GT, Colgan SP: Mucosal protection by hypoxiainducible factor prolyl hydroxylase inhibition. Gastroenterology 2008;134:145-155.

37 Olson N, Hristova M, Heintz NH, Lounsbury KM, van der Vliet A: Activation of hypoxia-inducible factor-1 protects airway epithelium against oxidant-induced barrier dysfunction. Am J Physiol Lung Cell Mol Physiol 2011;301:L993-L1002.

38 Yeh WL, Lu DY, Lin CJ, Liou HC, Fu WM: Inhibition of hypoxia-induced increase of blood-brain barrier permeability by YC-1 through the antagonism of HIF-1 $\alpha$ accumulation and VEGF expression. Mol Pharmacol 2007;72:440-449.

-39 Higashida T, Kreipke CW, Rafols JA, Peng C, Schafer S, Schafer P, Ding JY, Dornbos D, Li X, Guthikonda M, Rossi NF, Ding Y: The role of hypoxia-inducible factor-1alpha, aquaporin-4, and matrix metalloproteinase-9 in blood-brain barrier disruption and brain edema after traumatic brain injury. J Neurosurg 2011;114:92101.

40 Yan J, Zhou B, Taheri S, Shi H: Differential effects of HIF-1 inhibition by YC-1 on the overall outcome and blood-brain barrier damage in a rat model of ischemic stroke. PLoS One 2011;6:e27798.

41 Wang Z, Meng CJ, Shen XM, Shu Z, Ma C, Zhu GQ, Liu HX, He WC, Sun XB, Huo L, Zhang J, Chen G: Potential contribution of hypoxia-inducible factor-1alpha, aquaporin-4, and matrix metalloproteinase- 9 to bloodbrain barrier disruption and brain edema after experimental subarachnoid hemorrhage. J Mol Neurosci 2012;48:273-280.

42 Yan J, Zhang Z, Shi H: HIF-1 is involved in high glucose-induced paracellular permeability of brain endothelial cells. Cell Mol Life Sci 2012;69:115-128.

43 Chen W, Jadhav V, Tang J, Zhang JH: HIF-1 $\alpha$ inhibition ameliorates neonatal brain injury in a rat pup hypoxic-ischemic model. Neurobiol Dis 2008;31:433-441. 


\section{Cellular Physiology $\quad$ Cell Physiol Biochem 2013;32:859-870 and Biochemistry Hypoxia}

44 Yamagata K, Tagami M, Takenaga F, Yamori Y, Itoh S: Hypoxia-induced changes in tight junction permeability of brain capillary endothelial cells are associated with IL-1beta and nitric oxide. Neurobiol Dis 2004;17:491-499.

45 Fischer S, Wiesnet M, Marti HH, Renz D, Schaper W: Simultaneous activation of several second messengers in hypoxia-induced hyperpermeability of brain derived endothelial cells. J Cell Physiol 2004;198:359-369.

-46 Kannan KB, Colorado I, Reino D, Palange D, Lu Q, Qin X, Abungu B, Watkins A, Caputo FJ, Xu DZ, Semenza GL, Deitch EA, Feinman R: Hypoxia-inducible factor plays a gut-injurious role in intestinal ischemia reperfusion injury. Am J Physiol Gastrointest Liver Physiol 2011;300:G853-861.

47 Shah YM, Ito S, Morimura K, Chen C, Yim SH, Haase VH, Gonzalez FJ: Hypoxia-inducible factor augments experimental colitis through an MIF-dependent inflammatory signaling cascade. Gastroenterology 2008;134:2036-2048.

48 Rosenberger P, Khoury J, Kong T, Weissmuller T, Robinson AM, Colgan SP: Identification of vasodilatorstimulated phosphoprotein (VASP) as an HIF-regulated tissue permeability factor during hypoxia. FASEB J 2007;20:2613-2621.

-49 Kuhlmann CR, Tamaki R, Gamerdinger M, Lessmann V, Behl C, Kempski OS, Luhmann HJ: Inhibition of the myosin light chain kinase prevents hypoxia-induced blood-brain barrier disruption. J Neurochem 2007;102:501-507.

50 Zahs A, Bird MD, Ramirez L, Choudhry MA, Kovacs EJ: Anti-IL-6 antibody treatment but not IL-6 knockout improves intestinal barrier function and reduces inflammation following binge ethanol exposure and burn injury. Shock 2013;39:373-379.

51 Jeong HJ, Hong SH, Park RK, Shin T, An NH, Kim HM: Hypoxia-induced IL-6 production is associated with activation of MAP kinase, HIF-1, and NF-kappaB on HEI-OC1 cells. Hear Res 2005;207:59-67.

52 Feinman R, Deitch EA, Watkins AC, Abungu B, Colorado I, Kannan KB, Sheth SU, Caputo FJ, Lu Q, Ramanathan M, Attan S, Badami CD, Doucet D, Barlos D, Bosch-Marce M, Semenza GL, Xu DZ: HIF-1 mediates pathogenic inflammatory responses to intestinal ischemia-reperfusion injury. Am J Physiol Gastrointest Liver Physiol 2010;299:G833-G843. 